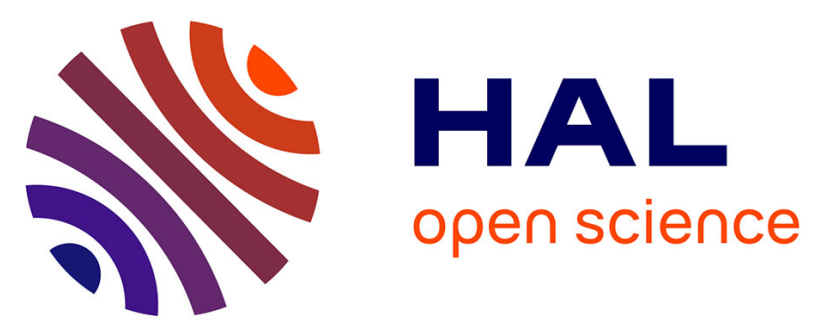

\title{
Synergic PDE3 and PDE4 control intracellular cAMP and cardiac excitation-contraction coupling in a porcine model
}

\author{
Delphine Mika, Pierre Bobin, Marta Lindner, Angèle Boet, Amir Hodzic, \\ Florence Lefebvre, Patrick Lechêne, Malha Sadoune, Jane-Lise Samuel, \\ Vincent Algalarrondo, et al.
}

\section{To cite this version:}

Delphine Mika, Pierre Bobin, Marta Lindner, Angèle Boet, Amir Hodzic, et al.. Synergic PDE3 and PDE4 control intracellular cAMP and cardiac excitation-contraction coupling in a porcine model. Journal of Molecular and Cellular Cardiology, 2019, 133, pp.57-66. 10.1016/j.yjmcc.2019.05.025 . hal-02460584

\section{HAL Id: hal-02460584 https://hal.science/hal-02460584}

Submitted on 1 Feb 2020

HAL is a multi-disciplinary open access archive for the deposit and dissemination of scientific research documents, whether they are published or not. The documents may come from teaching and research institutions in France or abroad, or from public or private research centers.
L'archive ouverte pluridisciplinaire HAL, est destinée au dépôt et à la diffusion de documents scientifiques de niveau recherche, publiés ou non, émanant des établissements d'enseignement et de recherche français ou étrangers, des laboratoires publics ou privés. 


\section{SYNERGIC PDE3 AND PDE4 CONTROL INTRACELLULAR CAMP AND CARDIAC EXCITATION-CONTRACTION COUPLING IN A PORCINE MODEL}

DELPHINE MIKA ${ }^{1 *}$, PIERRE BOBIN ${ }^{1 *}$, MARTA LINDNER ${ }^{1}$, ANGELE BOET $^{2}$, AMIR HODZIC $^{2}$, FLORENCE LEFEBVRE ${ }^{1}$, VINCENT ALGALARRONDO', CATHERINE RUCKER-MARTIN ${ }^{2}$, VIRGINIE LAMBERT ${ }^{2}$, RODOLPHE FISCHMEISTER ${ }^{1}$, GRÉGOIRE VANDECASTEELE ${ }^{1}$ AND JÉRÔME LEROY ${ }^{1}$

\section{${ }^{*}$ CO-AUTHORS}

${ }^{1}$ INSERM UMR-S 1180, FACULTÉ DE PHARMACIE, UNIV. PARIS-SUD, UNIVERSITE PARISSACLAY, F-92296, CHÂTENAY-MALABRY, FRANCE.

${ }^{2}$ INSERM UMR-S 999, CENTRE CHIRURGICAL MARIE LANNELONGUE, UNIV. PARIS SUD, LE PLESSIS-ROBINSON, FRANCE.

Footnote :

V. Lambert's present address is INSERM UMR_910, Faculté de Médecine la Timone, 13885 Marseille, France and Institut Mutualiste Montsouris, 42 boulevard Jourdan, 75014 Paris,France.

A. Hodzic's present address is Normandie University, Unicaen, INSERM COMETE, CHU Caen, France.

Running title: PDE4 controls cardiac function in pig

Correspondence to:

Dr. Grégoire VANDECASTEELE and Jérôme LEROY

INSERM UMR-S1180, LabEx LERMIT, DHU TORINO

UNIV. PARIS-SUD, UNIVERSITE PARIS-SACLAY,

Faculté de Pharmacie

5, Rue J.-B. Clément

F-92296 Châtenay-Malabry Cedex

France

Tel. 33-1-46 835771

Fax 33-1-46 835475

E-mail: jerome.leroy@u-psud.fr 


\title{
ABSTRACT
}

\begin{abstract}
Aims
Cyclic AMP phosphodiesterases (PDEs) are important modulators of the cardiac response to $\beta$ adrenergic receptor ( $\beta-A R)$ stimulation. PDE3 is classically considered as the major cardiac PDE in large mammals and human, while PDE4 is preponderant in rodents. However, it remains unclear whether PDE4 also plays a functional role in large mammals. Our purpose was to understand the role of PDE4 in CAMP hydrolysis and excitation-contraction coupling (ECC) in the pig heart, a relevant pre-clinical model.
\end{abstract}

\section{Methods and Results}

Real-time CAMP variations were measured in isolated adult pig right ventricular myocytes (APVMs) using a Förster resonance energy transfer (FRET) biosensor. ECC was investigated in APVMs loaded with Fura-2 and paced at $1 \mathrm{~Hz}$ allowing simultaneous measurement of intracellular $\mathrm{Ca}^{2+}$ and sarcomere shortening. The expression of the different PDE4 isoforms was assessed by Western blot in pig right ventricle and APVMs. Similarly to PDE3 inhibition with cilostamide (Cil), PDE4 inhibition with Ro 20-1724 (Ro) increased cAMP levels and inotropy under basal conditions. PDE4 inhibition enhanced the effects of the non-selective $\beta$-AR agonist isoprenaline (Iso) and the effects of $\mathrm{Cil}$, and increased spontaneous diastolic $\mathrm{Ca}^{2+}$ waves (SCWs) in these conditions. PDE3A, PDE4A, PDE4B and PDE4D isoforms are expressed in pig ventricle.. In APVMs isolated from a porcine model of repaired tetralogy of Fallot which leads to right ventricular failure, PDE4 inhibition also exerts inotropic and pro-arrhythmic effects.

\section{Conclusions}

Our results show that PDE4 controls ECC in APVMs and suggest that PDE4 inhibitors exert inotropic and pro-arrhythmic effects upon PDE3 inhibition or $\beta$-AR stimulation in our pre-clinical model. Thus, PDE4 inhibitors should be used with caution in clinics as they may lead to arrhythmogenic events upon stress. 


\section{INTRODUCTION}

The $\beta$-adrenergic receptor ( $\beta$-AR) signaling pathway is the main route for cardiac stimulation upon stress. It allows cardiac adaptation to increase blood supply to muscles during exercise. The so called "fight or flight" response starts with $\beta$-AR stimulation by catecholamines, leading to $G_{s}$ activation of adenylyl cyclases which catalyze the conversion of adenosine triphosphate (ATP) to the second messenger 3',5'-cyclic AMP (CAMP) and pyrophosphate. Subsequently, cAMP promotes protein kinase $A$ (PKA) activity which in turn phosphorylates key proteins of the excitation-contraction coupling (ECC) such as L-type $\mathrm{Ca}^{2+}$ channels (Cav1.2), ryanodine receptors (RYR2), phospholamban (PLB) and contractile proteins like troponin I and myosinbinding protein $C$ (MyBP-C).[1] These events underlie the classical positive inotropic and lusitropic effects of acute $\beta$-AR stimulation.

The levels of CAMP are not only determined by synthesis, but are also finely tuned by degradation enzymes called cyclic nucleotide phosphodiesterases (PDEs).[2-4] PDEs are subdivided into 11 families, among which five hydrolyse CAMP in the heart: PDE1, which is activated by $\mathrm{Ca}^{2+} /$ calmodulin; PDE2, which is stimulated by cGMP; PDE3, which is inhibited by cGMP; PDE4 and PDE8. While PDE1 and PDE2 can hydrolyse both CAMP and cGMP, PDE3 preferentially hydrolyses CAMP and both PDE4 and PDE8A are specific for CAMP. $[3,5]$ In the myocardium which species??, the PDE3 and PDE4 families prevail to degrade CAMP and regulate ECC. PDE3 predominates in other large mammals[6] and in human.[7] PDE3 inhibition was once privileged as a therapeutic strategy to boost the weakening pump in heart failure (HF) where the $\beta$-AR cascade is desensitized.[8] However, although the clinically used PDE3 inhibitors milrinone and enoximone improve systolic function and alleviate the symptoms in acute HF,[9] their chronic use increases mortality, presumably by favoring cardiac arrhythmias.[10] Despite the fact that these drugs are widely presented as selective inhibitors of PDE3, milrinone and enoximone also inhibit PDE4 with similar potency.[11] This raises the intriguing possibility that PDE4 inhibition might contribute to both inotropic and pro-arrhythmic effects of PDE3 inhibitors in HF.

Numerous studies performed in rodents demonstrated the predominance of PDE4 for the control of cAMP signals generated by $\beta$-ARs,[12-14] of PKA phosphorylation of ECC proteins, and of $\mathrm{Ca}^{2+}$ homeostasis and contraction.[15, 16] Pharmacological inhibition of PDE4 was shown to enhance the pro-arrhythmic effect of $\beta-A R$ stimulation in rat[16] and mouse ventricular cardiomyocytes.[17] The PDE4 family consists of four genes (Pde4a- $d$ ) but only Pde4a, Pde4b, and Pde4d appear to be expressed in rodents' heart.[18, 19] In mice, genetic ablation of Pde4b 
or Pde4d enhances the susceptibility to stress-induced ventricular tachycardia.[17, 19] This was attributed to hyperphosphorylation of RyR2 by PKA in Pde4d-deficient mice[17] and to exacerbated $\beta$-AR stimulation of L-type $\mathrm{Ca}^{2+}$ current in Pde4b-deficient mice. [19] Hyperphosphorylation of PLB was also reported in the latter study, probably because PDE4D associates with the PLB-SERCA2A complex to control its phosphorylation.[20] However, the role of PDE4 in the heart of human or large mammals remains elusive and even controversial. PDE4 is expressed in the human heart, $[7,17,21]$ but it constitutes only $\approx 10 \%$ of the total cAMP-PDE activity (versus 40-60\% in rat and mouse). [7, 17, 22] This appears to be due to a much higher activity of other PDEs in human versus rodents. [7] While it was initially reported that PDE4 does not control the contractile responses to catecholamines in atria from non-failing patients[23] or ventricular trabeculae from HF patients,[24] others showed redundancy of PDE3 and PDE4 to control the positive inotropic effects of serotonin in failing human hearts[25] and we demonstrated that these enzymes control $\beta-A R$ responses and arrhythmias in human atria. [21] Similarly, we found in dog ventricular myocytes that PDE4 controls cAMP levels upon $\beta$-AR stimulation and modulate $\beta$-AR stimulation of the L-type $\mathrm{Ca}^{2+}$ current when PDE3 is inhibited.[26]Pig constitutes another classical pre-clinical model that exhibits gross anatomic structure very similar to that of humans and have been the subject of translational studies.[27] It closely resembles human cardiac physiology and HF pathophysiology is very similar to that of humans, thus it is widely used to study new therapeutic targets. PDE4 is expressed in the pig heart.[28] Jointly with PDE3, it controls basal cAMP levels and modulates the response to serotonin in pig atria.[29] It is also critical to control atrial inotropic and cAMP responses to $\beta_{1}$-AR stimulation in newborn piglets.[30] Surprisingly, unlike what was found at the atrial level, PDE3 and PDE4 were reported as minor to control ventricular responses to catecholamines in newborn piglets and only PDE3 inhibition increased the inotropic effect of $\beta_{2}$-AR stimulation[30] and of serotonin $5-\mathrm{HT}_{4}$ receptors stimulation[29] Nonetheless, in open-chest pigs, intramyocardial infusion of rolipram, a PDE4 inhibitor, induced ventricular tachycardia suggesting a role of this enzyme to control cAMP levels.[31] Furthermore, in adolescent animals, both PDE3 and PDE4 control ventricular responses to 5-HT.[29] suggesting age-dependent changes of relative activities. Therefore, the respective role of PDE3 and PDE4 in the adult pig heart, especially upon $\beta$-AR stimulation, remains elusive. This study was thus designed to characterize the functional role of PDE4 in this classical pre-clinical model.

We isolated ventricular myocytes from adult pig hearts and measured cAMP levels, using a Förster resonance energy transfer (FRET)-based sensor; $\mathrm{Ca}^{2+}$ transients (CaT) and sarcomere shortening (SS). Our study demonstrates that PDE4, along with PDE3, controls basal cAMP 
levels and inotropic responses to $\beta$-AR stimulation. We also show that like PDE3, PDE4 limits ventricular arrhythmias by controlling $\mathrm{Ca}^{2+}$ homeostasis in normal adult pig right ventricular myocytes (APVMs) and in APVMs isolated from a model with right ventricular dysfunction reproducing repaired tetralogy of Fallot (rTOF).[32, 33] Like in rodents' heart, PDE3A, PDE4A, PDE4B and PDE4D isoforms are expressed in pig. Thus, our study suggests that many findings obtained in rodents concerning the role of PDE4 to control cardiac function might be transposable to pre-clinical model.

\section{METHODS}

All experiments were carried out according to the European Community guiding principles in the care and use of animals (2010/63/UE, 22 September 2010), the local Ethics committee (CEEA26 CAPSud) guidelines and the French decree $n^{\circ} 2013-118,1^{\text {st }}$ February 2013 on the protection of animals used for scientific purposes (JORF n0032, 7 February 2013 p2199, text

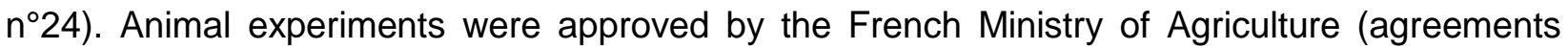
$\mathrm{N}^{\circ} 14-027$ and $\left.\mathrm{N}^{\circ} 2016-125-7914\right)$. A surgical procedure mimicking repaired Tetralogy of Fallot (rTOF) to obtain right ventricular dysfunction secondary to chronic overload[32] was performed on 7 Landrace piglets (operated group) that were between 50 to 67 days old. 12 age-matched animals were used as healthy controls.. All animals were male to avoid bias related to hormonal variations. Echocardiographic assessment of RV function was performed before euthanasia. After completion of the study, animals were euthanized using lethal propofol infusion and exsanguination. (For more details, please see supplemental material).

\section{Reagents}

Isoproterenol from Sigma-Aldrich (Saint-Quentin, France) was freshly prepared in a $1 \mathrm{mg} / \mathrm{mL}$ ascorbic acid solution at $10 \mathrm{mM}$ (Sigma-Aldrich, Saint-Quentin, France). Cilostamide (Cil) was from Tocris Bioscience (Bristol, UK): it blocks PDE3 with an IC50 ranging from $5 \mathrm{nM}[34]$ to 27 $\mathrm{nM},[35]$ and was used here at a $1 \mu \mathrm{M}$ concentration. Ro 20-1724 (Ro, 4-(3-butoxy-4methoxybenzyl)-2-imidazolidone) was from Calbiochem (Darmstadt, Germany): it blocks PDE4 with an IC50 value around $1 \mu \mathrm{M}[36]$ and was used here at $10 \mu \mathrm{M}$. At these concentrations, Cil and Ro were shown to be selective for PDE3 and PDE4 respectively.

\section{Myocyte isolation procedure}

Hearts were excised from adult (5 to 7 months old) pigs and ventricular myocytes were enzymatically isolated from the right ventricular $(\mathrm{RV})$ free wall as previously described. [32, 
33]Briefly, the right coronary artery ostium was cannulated and the tissue was perfused with a constant flow of approximately $200 \mathrm{ml} / \mathrm{min}$; temperature was maintained at $37^{\circ} \mathrm{C}$. After $10 \mathrm{~min}$ washing with a $\mathrm{Ca}^{2+}$-free Krebs-Ringer solution, tissue digestion was made by adding 0.354 $\mathrm{UI} / \mathrm{ml}$ of collagenase A (Roche Diagnostic). After 15-20 minutes of enzymatic perfusion, the RV was removed and myocytes from endocardia and myocardial layers were mechanically collected, filtered, washed with a buffer solution (HEPES-BSA 2\%), and resuspended in this buffer containing increasing $\mathrm{Ca}^{2+}$ concentrations up to $1.2 \mathrm{mM}$. Finally, isolated myocytes were plated on laminin-coated glass-bottom-dishes in Dulbecco's modified Eagle's medium (DMEM) supplemented with $5 \%$ fetal calf serum (FCS) for $1 \mathrm{~h}$ and maintained at $37^{\circ} \mathrm{C}$. After $1 \mathrm{~h}$, the medium was replaced by $300 \mu \mathrm{L}$ of FCS-free MEM or transduced with an adenovirus encoding the Epac-S ${ }^{\mathrm{H} 187}$ FRET-based sensor[37] at a multiplicity of infection (MOI) of $1000 \mathrm{pfu} / \mathrm{cell}$.

\section{Measurement of sarcomere shortening and $\mathrm{Ca}^{2+}$ transient}

All experiments were performed at $30 \pm 2^{\circ} \mathrm{C}$. Freshly isolated APVMs were loaded with $1 \mu \mathrm{mol} / \mathrm{L}$ Fura-2 AM (Invitrogen) for $15 \mathrm{~min}$ in a Ringer solution containing (in $\mathrm{mM}$ ): $\mathrm{NaCl} 121.6$; $\mathrm{KCl} 5.4$; Na-pyruvate 5; $\mathrm{NaHCO}_{3}$ 4.013; $\mathrm{NaH}_{2} \mathrm{PO}_{4}$ 0.8; $\mathrm{CaCl}_{2}$ 1.8; $\mathrm{MgCl}_{2}$ 1.8; glucose 5 and HEPES 10 $(\mathrm{pH} 7.4$ with $\mathrm{NaOH})$. Sarcomere shortening and Fura-2 ratio (measured at $512 \mathrm{~nm}$ upon excitation at 340 and $380 \mathrm{~nm}$ ) were simultaneously recorded in Ringer solution, using a double excitation spectrofluorimeter coupled with a video detection system (IonOptix, Milton, MA, USA). Myocytes were electrically stimulated with biphasic field pulses $(5 \mathrm{~V}, 4 \mathrm{~ms})$ at a frequency of 1 $\mathrm{Hz}$. $\mathrm{Ca}^{2+}$ transient amplitude was measured by dividing the twitch amplitude (difference between the peak systolic and the end-diastolic ratios) by the end-diastolic ratio, thus corresponding to the percentage of variation in the Fura-2 ratio. Similarly, sarcomere shortening was assessed by its percentage of variation, obtained by dividing the twitch amplitude $(\Delta \mathrm{L}$, difference between the end-diastolic and the peak systolic sarcomere length) by the end-diastolic sarcomere length $\left(\mathrm{L}_{0}\right)$. Relaxation kinetics were estimated by a non-linear fit of the decaying part of the $\mathrm{Ca}^{2+}$ transient and sarcomere shortening traces with the following equation: $Y(t)=A^{*} \exp (-t / \tau)+A_{0}$, where $t$ is the time, $A_{0}$ the asymptote of the exponential, $A$ the relative amplitude of the exponential, and $\tau$ the time constant of the exponential.

\section{FRET imaging}

FRET experiments were performed at room temperature $24 \mathrm{~h}$ after cell plating. Cells were maintained in a Ringer solution containing (in $\mathrm{mM}$ ): $\mathrm{NaCl}$ 121.6, $\mathrm{KCl} 5.4, \mathrm{MgCl}_{2}$ 1.8; $\mathrm{CaCl}_{2}$ 1.8; $\mathrm{NaHCO}_{3} 4, \mathrm{NaH}_{2} \mathrm{PO}_{4}$ 0.8, D-glucose 5, sodium pyruvate 5, HEPES 10, adjusted to $\mathrm{pH} 7.4$. Images were captured every $5 \mathrm{~s}$ using the $40 \mathrm{x}$ oil immersion objective of a Nikon TE 300 
inverted microscope connected to a software-controlled (Metafluor, Molecular Devices, Sunnyvale, CA, USA) cooled charge coupled (CCD) camera (Sensicam PE, PCO, Kelheim, Germany). Cells were excited during 150-300 ms by a Xenon lamp (100 W, Nikon, Champignysur-Marne, France) using a 440/20BP filter and a 455LP dichroic mirror. Dual emission imaging was performed using an Optosplit II emission splitter (Cairn Research, Faversham, UK) equipped with a 495LP dichroic mirror and BP filters 470/30 (CFP) and 535/30 (YFP), respectively. Spectral bleed-through into the YFP channel was subtracted using the formula: YFP $_{\text {corr }}=$ YFP-0.6xCFP.

\section{Cell extracts and western blot analysis}

RV tissue or isolated APVMs were homogenized in an ice-cold buffer containing $150 \mathrm{mM} \mathrm{NaCl}$, 20 mM HEPES (pH 7.4), 2 mM EDTA and 0.2 mM EGTA, supplemented with 10\% glycerol, 0.2\% Triton X-100 and Complete Protease Inhibitor Tablets (Roche Diagnostics). Lysates were rotated at $4^{\circ} \mathrm{C}$ for $30 \mathrm{~min}$ followed by a $10 \mathrm{~min}$ centrifugation at $20,000 \times \mathrm{g}$ and $4^{\circ} \mathrm{C}$. Supernatants were directly used for Western blotting. $15 \mu \mathrm{g}$ protein extracts were loaded. PDE3A was detected using a rabbit polyclonal anti-PDE3A antibody from Fabgenix. For specific PDE4A and PDE4B detection, rabbit polyclonal antibodies generated against their respective Ctermini were used (anti-PDE4A: AC55; anti-PDE4B: 113-4). Mouse monoclonal antibody (ICOS PDE4D) was used to specifically detect PDE4D. PDE3A antibody was a generous gift from $\mathrm{Dr}$ Chen Yan (Rochester University, NY, USA). PDE4A, PDE4B and PDE4D antibodies were kindly provided by Pr Marco Conti (University of California San Francisco, CA, USA).

\section{Statistics}

All results are expressed as mean \pm SEM. Statistical analysis was performed using GraphPad Prism software (GraphPad software, Inc., La Jolla, CA, USA). Normal distribution was tested by a Shapiro-Wilk normality test. For normally distributed data, differences between multiple groups were analyzed using a nested ANOVA (which takes into account both the number of observations and the number of animals) was performed using the Imer function in the nlme v3.1-131 package for $R$ ( $R$ version 3.4.1 and RStudio version 1.0.153), followed by Tukey's post-hoc test for all data obtained on individual cells. When the data obtained did not follow a normal distribution, a Kruskal-Wallis followed by a Dunn's post hoc test was used. To analyze results obtained with western blots, the mean values of two groups were analyzed by a MannWhitney test. A Chi ${ }^{2}$ test followed by a Fischer exact test was used to compare number of arrhythmic cells. Differences with $p$-values $<0.05$ were considered as statistically significant. The 
number of independent experiments performed and the statistical tests performed are indicated in the figures and their legends respectively. 


\section{RESULTS}

\section{Both PDE3 and PDE4 control cAMP levels in APVMs}

To evaluate cAMP levels in isolated cardiomyocytes, the FRET-based sensor Epac-S ${ }^{\mathrm{H} 187}$ was expressed in APVMs using a recombinant adenovirus. As shown in Figure 1, continuous application of the non-selective $\beta$-AR agonist isoprenaline (Iso, $10 \mathrm{nM}$ ) increased the CFP/YFP ratio by $45.5 \pm 4.8 \%(n=20, \quad p<0.05)$ indicating an increased global cytosolic cAMP concentration. Addition of Ro 20-1724 (Ro, $10 \mu \mathrm{mol} / \mathrm{L}$ ), a selective inhibitor of PDE4, increased the CFP/YFP ratio up to $184 \pm 12.6 \%(n=20, p<0.001)$ demonstrating a major role for this enzyme to degrade CAMP produced upon $\beta$-AR stimulation. The selective PDE3 inhibitor cilostamide (Cil, $1 \mu \mathrm{mol} / \mathrm{L}$ ) also increased the CFP/YFP ratio to similar levels $(187.9 \pm 15.3 \%$, $n=20, p<0.001)$. In the absence of $\beta$-AR stimulation, Ro or Cil alone induced a slight $(<20 \%)$ but significant increase in basal CFP/YFP ratio (Figure 1B and D). However, concomitant inhibition of PDE3 and PDE4 resulted in a substantial CAMP elevation $(+130.2 \pm 13.9 \%, n=12, p<0.001$, Figure $1 \mathrm{~B}$ and $\mathrm{D})$. These results indicate that both PDE3 and PDE4 are important to counterbalance basal and $\beta$-AR-stimulated cAMP synthesis in APVMs.

PDE3 and PDE4 were reported to be decreased in pathological conditions such as hypertrophy and HF[17, 38-40] although this may depend on disease etiology and stage.[41-43] Thus, in a next series of experiments, we investigated the respective contribution of these enzymes in APVMs isolated from a pig model of right ventricle dysfunction induced by chronic overload as observed in humans with repaired tetralogy of Fallot (rTOF). [32, 33] As indicated in Supplemental Table 1, four months after pulmonary valve surgery and pulmonary artery banding, RV dimensions were largely increased, and Tricuspid Annular Plane Systolic Excursion (TAPSE) was decreased, attesting RV remodeling and dysfunction due to combined volume and pressure overload. Measurements of cAMP levels by FRET in APVMs from these animals showed no apparent effect of PDE3 and PDE4 inhibitors under basal conditions, whereas concomitant application of Ro and Cil was still able to increase cAMP (Supplemental Figure 1). The response to $\beta$-AR stimulation (Iso, $10 \mathrm{nM}$ ) was virtually absent in APVMs from the rTOF model, but cAMP could still be increased by concomitant application of PDE3 or PDE4 inhibitors.. 


\section{Both PDE3 and PDE4 inhibition produce inotropic effects under basal conditions and promote pro-arrhythmogenic $\mathrm{Ca}^{2+}$ waves in APVMs}

To investigate the role of PDE4 in ECC in APVMs, calcium transients (CaT) and sarcomere shortening (SS) were simultaneously recorded in cells loaded with $1 \mu \mathrm{mol} / \mathrm{L}$ Fura-2 and paced at $1 \mathrm{~Hz}$ (Figure 2A). Average diastolic sarcomere length was $1.79 \pm 0.01 \mu \mathrm{m}(\mathrm{n}=13)$. Under control conditions (Ctrl), mean CaT amplitude was $35.5 \pm 6.0 \%$ above diastolic Fura-2 ratio, and SS was $3.1 \pm 0.9 \%$ of diastolic sarcomere length $(n=13)$. CaT and SS declined to diastolic levels with average time constants $(\tau)$ of $0.42 \pm 0.04 \mathrm{~s}$ and $0.15 \pm 0.03 \mathrm{~s}$, respectively (Figure 2B and $\mathrm{C}$ ). Under basal conditions, Ro increased SS by about 3-fold (to $10.8 \pm 3.1 \%, n=6, p<0.01$ ) and increased CaT amplitude to $60.2 \pm 11.4 \%$, although this increase did not reach statistical significance $(n=6)$. Similarly, inhibition of PDE3 by Cil potentiated both SS $(8.7 \pm 1.4 \%, n=7$, $\mathrm{p}<0.01)$ and $\mathrm{CaT}$ amplitude but not significantly $(68.9 \pm 12.1 \%, n=7, p=0.06)$. These inotropic effects were accompanied with a slight but not significant lusitropic effect (Figure 2C). Combination of both Ro and Cil produced a robust inotropic effect, increasing SS up to $13.7 \pm$ $1.0 \%$ and systolic $\mathrm{Ca}^{2+}$ levels up to $72.0 \pm 8.9 \%$ above diastolic ratio $(n=13, p<0.01)$. Cil+Ro accelerated the return to diastolic $\mathrm{Ca}^{2+}$ by decreasing the $\tau$ value to $0.18 \pm 0.03 \mathrm{~s}(\mathrm{n}=13$, $p<0.01)$. However, the lusitropic effects of Cil, Ro or the combination of both inhibitors were not strong enough to reach statistical significance, suggesting that the low turnover of cAMP synthesis under basal conditions revealed by FRET imaging (Figure 1) could influence $\mathrm{Ca}^{2+}$ refilling of the SR but not contractile protein phosphorylation.

The crucial role for PDE4 and PDE3 to control CAMP levels and $\mathrm{Ca}^{2+}$ homeostasis was further demonstrated by the appearance of spontaneous $\mathrm{Ca}^{2+}$ waves (SCWs) upon cessation of pacing when PDE inhibitors were applied. When cells were subjected to Ro or Cil alone, very few SCWs were observed (Figure 3) but upon concomitant Ro and Cil perfusion, $\sim 80 \%$ of the cardiomyocytes $(n=14, p<0.01)$ exhibited spontaneous $\mathrm{Ca}^{2+}$ waves (SCWs) between two stimulations or during a $10 \mathrm{~s}$ pause of stimulation $(2.3 \pm 0.9 \mathrm{SCWs}$ per $10 \mathrm{~s}, \mathrm{p}<0.01)$. Because inhibition of both enzymes leads to pro-arrhythmic events, it demonstrates that both PDE4 and PDE3 contribute to $\mathrm{Ca}^{2+}$ homeostasis in APVMs. Interestingly, similar results were observed in APVMs isolated from rTOF animals. Whereas SS and CaT amplitude measured in APVMs isolated from healthy or rTOF animals were identical (Supplemental Table 2), relaxation and CaT decay were slower in rTOF (Supplemental Table 2), evoking a decreased velocity of SR $\mathrm{Ca}^{2+}$ uptake as we previously observed in this model.[33] 
In rTOF APVMs, PDE4 or PDE3 inhibition had no significant inotropic or lusitropic effects under basal conditions, but concomitant application of these inhibitors nearly doubled CaT amplitude $(n=12, p<0.01$, Figure $4 B)$, produced a 5 -fold increase in SS amplitude $(n=12, p<0.001$, Figure $4 C)$ and significantly accelerated CaT and SS relaxation ( $n=12, p<0.05$, Figures 4B, 4C). Inhibition of both enzymes was also required to induce pro-arrhythmogenic SCWs in $50 \%$ of these cells $(n=14, p<0.01$, Figure $4 E, 4 F)$, demonstrating that not only in physiological but also under pathological conditions, both PDE4 and PDE3 control ECC and contribute to $\mathrm{Ca}^{2+}$ homeostasis in APVMs.

\section{PDE4 and PDE3 modulate $\beta$-AR stimulation of ECC in APVMs}

To investigate the functional consequences of PDE4 inhibition compared to PDE3 inhibition on $\beta$-AR-stimulated ECC in APVMs, cells were first subjected to a submaximal concentration of the non-selective $\beta$-AR agonist Iso (10 nM) and then to either inhibition of PDE4 with Ro or of PDE3 with Cil, as illustrated by the individual traces of $\mathrm{CaT}$ and $\mathrm{SS}$ in Figure $5 \mathrm{~A}$ and $5 \mathrm{~B}$. As shown in Figure 5C, on average, Iso increased CaT amplitude from $19.3 \pm 2.6 \%$ to $70.5 \pm 7.1 \%$ ( $n=16$, $p<0.001$ vs Ctrl), and SS was increased from $1.5 \pm 0.3 \%$ to $11.9 \pm 1.1 \%$ ( $n=16, p<0.001$ vs Ctrl). Iso also strongly accelerated the relaxation rates of both parameters, with $\tau$ values decreasing from $0.4 \pm 0.03 s$ to $0.26 \pm 0.04 \mathrm{~s}$ for CaT ( $n=16, p<0.05 v s$ Ctrl) and from $0.24 \pm 0.05 s$ to $0.04 \pm$ $0.005 \mathrm{~s}$ for $\mathrm{SS}$ ( $\mathrm{n}=15, \mathrm{p}<0.001 \mathrm{vs}$ Ctrl). These inotropic and lusitropic effects were potentiated by PDE4 inhibition. CaT was further increased to $78.5 \pm 7.1 \%$ and SS to $15.0 \pm 0.8 \%$ under Iso+Ro $(n=16)$. Decay kinetics of CaT were also further accelerated by Ro $(\tau=0.12 \pm 0.01 \mathrm{~s}, n=16$, $p<0.05$ vs Iso, Figure $5 C$ ). This was also the case for SS relaxation, although the difference with Iso alone was modest because $\beta$-AR stimulation alone already accelerated drastically myocyte relaxation. PDE3 inhibition with Cil induced very similar effects as Ro (Figure 5D).

In these experiments, we also analyzed the occurrence of SCWs upon cessation of stimulation (Figure 6). Figure $6 \mathrm{~A}$ and $6 \mathrm{~B}$ illustrate representative recordings of $\mathrm{CaT}$ in normal Ringer, upon stimulation with Iso $10 \mathrm{nM}$ alone and in combination with either Ro (Figure 6A) or Cil (Figure 6B). When cells were subjected to Iso alone, only sparse SCWs were observed ( 1.5 per $10 \mathrm{~s})$ in $\sim 40 \%$ of cells. However, when Ro was applied in combination with Iso, $75 \%$ of the cells exhibited pro-arrhythmogenic SCWs at a frequency of $2.2 \pm 0.5$ per $10 \mathrm{~s}$ (Figure 6C). Again, these pro-arrhythmic effects were very similar to those observed upon PDE3 inhibition (Iso+Cil) which triggered SCWs at a frequency of $3.9 \pm 1.6$ per $10 \mathrm{~s}$ in $73.3 \%$ of cells ( $\mathrm{p}<0.05$ vs Iso) (Figure 6D). 


\section{PDE3A, PDE4A, PDE4B and PDE4D isoforms are expressed in pig right ventricle}

PDE3A is a major PDE3 isoform degrading CAMP in human[44] and rodent[45] cardiomyocytes to control ECC coupling. PDE4 activity is due to the expression of PDE4A, PDE4B, and PDE4D variants in mouse[19], rat[18, 40] and human[7] heart. To investigate whether these isoforms are also expressed in the porcine myocardium, we performed Western blot analysis using subtype-specific antibodies against PDE3A, PDE4A, PDE4B, and PDE4D. All four variants were detected in right ventricle homogenates (Figure 7A), indicating conservation between rodents, human and pig cardiac tissue. Importantly, the three PDE4 isoforms were also detected in protein extracts obtained from isolated cardiomyocytes (Figure 7B) demonstrating their expression in contractile cells.

\section{DISCUSSION}

Cyclic nucleotide phosphodiesterases are essential enzymes degrading CAMP not only to terminate $\beta$-AR stimulation of cardiac function, but also to compartmentalize cAMP signals within discrete domains inside cardiomyocytes. $[3,4]$ Literature is sparse and functional data are often missing in studies dedicated to the role of PDEs especially PDE4 in large mammals and human heart, . This is due to the limited access to human biopsies and the difficulty to isolate cardiomyocytes from explanted human ventricles. Compared to rodents, pig cardiac anatomy and physiology is much more similar to humans.[27] Therefore, it constitutes a good alternative model and a bridge to fill the gap between proof-of-concept studies performed in rodents and clinical trials in patients. Because genetic engineering of pigs is developing, its use as a preclinical model will rise.[46] However, despite a large amount of work realized in rodents that unveiled the preponderant role of PDE4 to control cardiac function, its participation in large mammals, especially in pig heart, remains elusive. Our study provides a unique panel of data describing for the first time at the cellular level, the respective role of PDE3 and PDE4 in this large mammal preclinical model.

\section{Similar PDE4 isoforms are expressed in pig ventricular tissue than in rodents and human heart}

We show here that the three PDE4 isoforms, PDE4A, PDE4B and PDE4D known to be expressed in rodents[19] and humans[17] are also expressed in pig ventricular tissue and 
myocytes. This suggests that the expression profile of PDE4 isoforms is conserved in this preclinical model. In the rodent heart, PDE4 variants are localized in discrete microdomains, allowing fine tuning of cAMP signaling to control the phosphorylation and hence the activity of individual proteins such as $\beta-A R s,[47] \mathrm{Ca}_{v} 1.2$, [19] RyR2,[17] and PLB/SERCA2[20] within these compartments. PDE4 has also been found tethered to similar macromolecular signaling complexes in humans, including the RyR2, [17] PLB/SERCA2 and the $\beta_{1}-A R$ complexes.[7] The inotropic and lusitropic effects of PDE4 inhibition reported here suggests that PDE4 might also control Cav1.2, RyR2, PLB phosphorylation by PKA and activity in APVMs. In rodents, different $\beta$-AR subtypes, namely $\beta_{1}-A R$ and $\beta_{2}-A R$, mediate these effects under the control of both PDE3 and PDE4.[14, 15, 48] $\beta_{2}$-AR are localized within the t-tubules in rodent ventricular cells where cAMP is confined by PDE4,[49] and more specifically by PDE4B and PDE4D isoforms.[50] Interestingly, we show here that PDE4B and PDE4D isoforms are also expressed in pig ventriculocytes. Whether cAMP emanating from $\beta_{1}-A R$ and $\beta_{2}-A R$ within the t-tubules is confined by the same PDE4 isoforms in pigs will require further investigations. A more detailed comparison in terms of level of expression of various PDE families, association with the key proteins of the ECC and function is also required to determine whether this model fully recapitulates the role of PDEs in the rodent and human hearts.

\section{Both PDE3 and PDE4 control CAMP and ECC in pig ventricular myocytes}

It is widely recognized that PDE3 is the main PDE isozyme controlling ventricular contractility in large animal models, which are believed to exhibit a pattern of PDE expression close to human, where PDE3 dominates.[6, 21, 51] PDE3 being one of the main enzyme degrading cAMP in human heart, .[7] PDE3 inhibitors are potent cardiotonic agents with proven beneficial hemodynamic actions,[9] but their use is now limited to acute heart failure or post-surgery since chronic treatment promotes sudden cardiac death due to arrhythmias.[10] As expected, we confirm here that PDE3 inhibition increases cAMP levels under basal conditions and upon $\beta-A R$ stimulation and exerts inotropic and lusitropic effects in APVMs. This is compatible with PDE3 being a major enzyme controlling cAMP levels in this species where, like in other large mammals such as bovine[52] and dog,[26, 51] [53]it is predominantly expressed. We also show that the PDE3A isoform is present in porcine ventricular tissue, like in human heart where it is the main isoform controlling PLB phosphorylation.[54] Similarly to PDE3 inhibition, PDE4 inhibition also increases basal cAMP levels, contraction and relaxation in APVMs. While these effects of either PDE3 or PDE4 inhibitors are relatively modest, their concomitant application has a drastic impact on cAMP levels and consequently amplifies calcium transient amplitude and 
sarcomere shortening. This reveals that both PDE3 and PDE4 are redundant and concur to counterbalance cAMP synthesis under basal conditions as previously shown.[29] Upon $\beta-A R$ stimulation, inhibition of either enzyme leads to an increase of CAMP levels potentiating ECC in APVMs, similarly to what was reported in ventricular cardiomyocytes isolated from rat,[14, 15] dog hearts[26] and from human atrial cells.[21] Our observations demonstrate the importance of the PDE4 family to control cardiac ECC in pig ventriculocytes like it has been described in rodent ventricular myocytes.[14-16] revealing that the role of this enzyme is conserved across species. In accordance with the decreased PDE3 and PDE4 activities in a rat model of cardiac hypertrophy induced by chronic aortic constriction[40] and in HF patients,[17, 38] we show here that in a porcine model of right ventricular dysfunction secondary to chronic overload, mimicking the rTOF, [32, 33] PDE3 and PDE4 inhibitors are less effective to increase cAMP levels as previously reported in hypertrophied rat cardiomyocytes[40] and HF dogs. [38] This is also probably due to reduced cAMP synthesis as observed generally in HF[8] and suggested here by the reduced capacity of Iso to increase cAMP in APVMs from rTOF pigs (Supplemental Figure 1). This is probably this desensitization which might have hindered previous attempts to detect the effects of PDE4 inhibitors in human explanted biopsies from HF patients. [24] However, despite this desensitization, concomitant application of PDE3 and PDE4 inhibitors still resulted in significant increase in cAMP and in positive inotropic and lusitropic effects, suggesting that PDE4 and PDE3 control cardiac function not only in physiological but also in pathological conditions.

\section{PDE4 inhibition is pro-arrhythmic in pig ventricular cardiomyocytes}

Unlike the pro-arrhythmic effects of PDE3 inhibitors which are well documented and precluded their chronic use in HF,[10] the potential deleterious effects of PDE4 inhibitors on cardiac function in large mammals are scarce in the literature. Pro-arrhythmic effects of rolipram, a selective PDE4 inhibitor, have been observed in anesthetized open-chest adult pigs[31] and in isolated human atrium. [21] Our results here clearly demonstrate that PDE4 inhibition is proarrhythmic in APVMs but this requires prior elevation of cAMP with either PDE3 inhibition or $\beta$ AR stimulation, similarly to what we observed in rat ventricular cells.[16] Strikingly, the sole PDE3 inhibition produces only few arrhythmias and requires concomitant PDE4 inhibition to evoke SCWs in the majority of cells. Whether concomitant PDE4 and PDE3 inhibition is also required in human ventricular cells is therefore questionable. Indeed, it has been shown that milrinone and enoximone are not only PDE3 inhibitors but also showed similar potency to inhibit 
PDE4. [11] Whether the deleterious effects of chronic PDE3 inhibition in patients were in fact due to concomitant PDE3 and PDE4 inhibition is thus suggested by the present study performed in an animal model closer to human than rodents. PDE4 inhibitors are new promising therapeutic agents and are currently developed to treat inflammation, chronic obstructive pulmonary disease, psoriasis, and neurological illnesses.[55] Our study also underlies that pre-clinical studies realized in large animals such as pig should carefully address the potential cardiac adverse effects of these new drugs especially under stress conditions, i.e. upon $\beta$-AR stimulation or combination with PDE3 inhibitors, when PDE4 inhibition has an impact on heart function.

\section{CONCLUSION}

Our results demonstrate that the previously reported conservation of the expression pattern of PDE4 isoforms among rodent and human hearts[7] is also applicable to pig ventricle. Our study demonstrates that PDE4 controls CAMP levels and ECC in healthy pigs and in a pathological model of RV overload. Therefore, it validates the pig as a relevant pre-clinical model to study the impact of PDE4 inhibitors on cardiac function under physiological and pathophysiological conditions. Importantly, it suggests some vigilance in the use of PDE4 inhibitors in clinic as they may lead to arrhythmogenic events.

\section{FUNDINGS}

DM was supported by a post-doctoral grant from Région lle-de-France (CORDDIM), a postdoctoral grant from Fondation Lefoulon-Delalande, and ANR-16-CE14-0014 grant. PB was supported by a PhD fellowship from Région lle-de-France (CORDDIM) and Fondation pour la Recherche Médicale. Our laboratory is a member of the Laboratory of Excellence LERMIT supported by a grant from ANR (ANR-10-LABX-33) under the program "Investissements d'Avenir" ANR-11-IDEX-0003-01. This work was also funded by grant ANR13BSV10003-02 to GV.

\section{ACKNOWLEDGMENTS}

We thank Dr. Kees Jalink (Division of Cell Biology, The Netherlands Cancer Institute, Amsterdam, The Netherlands) for sharing the Epac-SH187 FRET-based sensor, Dr. Chen Yan (Rochester University, NY, USA) and Pr. Marco Conti (University of California San Francisco, CA, USA) for generously providing PDE antibodies, Dr. Emmanuel Le Bret (Congenital Heart 
Diseases, Hospital of Marie Lannelongue, Le Plessis-Robinson, France) for the surgical procedure on the rTOF model and the Surgical Research Laboratory of the hospital of Marie Lannelongue for technical assistance and animal care. 


\section{REFERENCES}

[1] D.M. Bers, Cardiac excitation-contraction coupling, Nature 415(6868) (2002) 198-205.

[2] R. Fischmeister, L.R. Castro, A. Abi-Gerges, F. Rochais, J. Jurevicius, J. Leroy, G. Vandecasteele, Compartmentation of cyclic nucleotide signaling in the heart: the role of cyclic nucleotide phosphodiesterases, Circulation research 99(8) (2006) 816-28.

[3] D. Mika, J. Leroy, G. Vandecasteele, R. Fischmeister, PDEs create local domains of cAMP signaling, Journal of molecular and cellular cardiology 52(2) (2012) 323-9.

[4] J. leroy, G. Vandecasteele, R. Fischmeister, Cyclic AMP signaling in cardiac myocytes, Current Opinion in Physiology 1 (2018) 161-171.

[5] E. Patrucco, M.S. Albergine, L.F. Santana, J.A. Beavo, Phosphodiesterase 8A (PDE8A) regulates excitation-contraction coupling in ventricular myocytes, Journal of molecular and cellular cardiology 49(2) (2010) 330-3.

[6] O.E. Osadchii, Myocardial phosphodiesterases and regulation of cardiac contractility in health and cardiac disease, Cardiovasc Drugs Ther 21 (2007) 171-94.

[7] W. Richter, M. Xie, C. Scheitrum, J. Krall, M.A. Movsesian, M. Conti, Conserved expression and functions of PDE4 in rodent and human heart, Basic research in cardiology 106(2) (2011) 249-62.

[8] M.J. Lohse, S. Engelhardt, T. Eschenhagen, What is the role of $ß$-adrenergic signaling in heart failure?, Circulation research 93(10) (2003) 896-906.

[9] M. Movsesian, J. Stehlik, F. Vandeput, M.R. Bristow, Phosphodiesterase inhibition in heart failure, Heart failure reviews 14(4) (2009) 255-63.

[10] M. Packer, J.R. Carver, R.J. Rodeheffer, R.J. Ivanhoe, R. DiBianco, S.M. Zeldis, G.H. Hendrix, W.J. Bommer, U. Elkayam, M.L. Kukin, a.l. et, Effect of oral milrinone on mortality in severe chronic heart failure. The PROMISE Study Research Group, The New England journal of medicine 325(21) (1991) 14681475.

[11] T. Bethke, T. Eschenhagen, A. Klimkiewicz, C. Kohl, H. von der Leyen, H. Mehl, U. Mende, W. Meyer, J. Neumann, S. Rosswag, W. Schmitz, H. Scholz, J. Starbatty, B. Stein, H. Wenzlaff, V. Döring, P. Kalmar, A. Haverich, Phosphodiesterase inhibition by enoximone in preparations from nonfailing and failing human hearts, Arzneimittelforschung 42(4) (1992) 437-445.

[12] F. Rochais, G. Vandecasteele, F. Lefebvre, C. Lugnier, H. Lum, J.L. Mazet, D.M. Cooper, R. Fischmeister, Negative feedback exerted by cAMP-dependent protein kinase and cAMP phosphodiesterase on subsarcolemmal cAMP signals in intact cardiac myocytes: an in vivo study using adenovirus-mediated expression of CNG channels, The Journal of biological chemistry 279(50) (2004) 52095-105.

[13] M. Mongillo, T. McSorley, S. Evellin, A. Sood, V. Lissandron, A. Terrin, E. Huston, A. Hannawacker, M.J. Lohse, T. Pozzan, M.D. Houslay, M. Zaccolo, Fluorescence resonance energy transfer-based analysis of cAMP dynamics in live neonatal rat cardiac myocytes reveals distinct functions of compartmentalized phosphodiesterases, Circulation research 95(1) (2004) 65-75.

[14] J. Leroy, A. Abi-Gerges, V.O. Nikolaev, W. Richter, P. Lechene, J.L. Mazet, M. Conti, R. Fischmeister, G. Vandecasteele, Spatiotemporal dynamics of beta-adrenergic cAMP signals and L-type $\mathrm{Ca}^{2+}$ channel regulation in adult rat ventricular myocytes: role of phosphodiesterases, Circulation research 102(9) (2008) 1091-100.

[15] D. Mika, P. Bobin, M. Pomerance, P. Lechene, R.E. Westenbroek, W.A. Catterall, G. Vandecasteele, J. Leroy, R. Fischmeister, Differential regulation of cardiac excitation-contraction coupling by cAMP phosphodiesterase subtypes, Cardiovascular research 100(2) (2013) 336-46.

[16] P. Bobin, A. Varin, F. Lefebvre, R. Fischmeister, G. Vandecasteele, J. Leroy, Calmodulin kinase II inhibition limits the pro-arrhythmic $\mathrm{Ca}^{2+}$ waves induced by CAMP-phosphodiesterase inhibitors, Cardiovascular research 110(1) (2016) 151-61. 
[17] S.E. Lehnart, X.H.T. Wehrens, S. Reiken, S. Warrier, A.E. Belevych, R.D. Harvey, W. Richter, S.L.C. Jin, M. Conti, A. Marks, Phosphodiesterase 4D deficiency in the ryanodine receptor complex promotes heart failure and arrhythmias, Cell 123(1) (2005) 23-35.

[18] M.M. Kostic, S. Erdogan, G. Rena, G. Borchert, B. Hoch, S. Bartel, G. Scotland, E. Huston, M.D. Houslay, E.G. Krause, Altered expression of PDE1 and PDE4 cyclic nucleotide phosphodiesterase isoforms in 7-oxo-prostacyclin-preconditioned rat heart, Journal of molecular and cellular cardiology 29(11) (1997) 3135-3146.

[19] J. Leroy, W. Richter, D. Mika, L.R.V. Castro, A. Abi-Gerges, M. Xie, C. Scheitrum, F. Lefebvre, J. Schittl, R. Westenbroek, W.A. Catterall, F. Charpentier, M. Conti, R. Fischmeister, G. Vandecasteele, Phosphodiesterase 4B in the cardiac L-type $\mathrm{Ca}^{2+}$ channel complex regulates $\mathrm{Ca}^{2+}$ current and protects against ventricular arrhythmias, The Journal of clinical investigation 121(7) (2011) 2651-61.

[20] S. Beca, P.B. Helli, J.A. Simpson, D. Zhao, G.P. Farman, P. Jones, X. Tian, L.S. Wilson, F. Ahmad, S.R.W. Chen, M.A. Movsesian, V. Manganiello, D.H. Maurice, M. Conti, P.H. Backx, Phosphodiesterase 4D regulates baseline sarcoplasmic reticulum Ca2+ release and cardiac contractility, independently of L-type Ca2+ current, Circulation research 109(9) (2011) 1024-1030.

[21] C.E. Molina, J. Leroy, W. Richter, M. Xie, C. Scheitrum, I.O. Lee, C. Maack, C. Rucker-Martin, P. Donzeau-Gouge, I. Verde, A. Llach, L. Hove-Madsen, M. Conti, G. Vandecasteele, R. Fischmeister, Cyclic adenosine monophosphate phosphodiesterase type 4 protects against atrial arrhythmias, Journal of the American College of Cardiology 59(24) (2012) 2182-90.

[22] W.B. Johnson, S. Katugampola, S. Able, C. Napier, S.E. Harding, Profiling of cAMP and cGMP phosphodiesterases in isolated ventricular cardiomyocytes from human hearts: comparison with rat and guinea pig, Life Sci 90(9-10) (2012) 328-36.

[23] T. Christ, A. Engel, U. Ravens, A.J. Kaumann, Cilostamide potentiates more the positive inotropic effects of (-)-adrenaline through $\beta_{2}$-adrenoceptors than the effects of $(-)$-noradrenaline through $\beta_{1^{-}}$ adrenoceptors in human atrial myocardium, Naunyn Schmiedebergs Arch Pharmacol 374(3) (2006) 24953.

[24] P. Molenaar, T. Christ, R.I. Hussain, A. Engel, E. Berk, K.T. Gillette, L. Chen, A. Galindo-Tovar, K.A. Krobert, U. Ravens, F.O. Levy, A.J. Kaumann, PDE3, but not PDE4, reduces $\beta_{1}$ and $\beta_{2}$-adrenoceptormediated inotropic and lusitropic effects in failing ventricle from metoprolol-treated patients, British journal of pharmacology 169(3) (2013) 528-38.

[25] F. Afzal, K.W. Andressen, H.K. Mork, J.M. Aronsen, I. Sjaastad, C.P. Dahl, T. Skomedal, F.O. Levy, J.B. Osnes, E. Qvigstad, 5- $\mathrm{HT}_{4}$-elicited positive inotropic response is mediated by cAMP and regulated by PDE3 in failing rat and human cardiac ventricles, British journal of pharmacology 155(7) (2008) 1005-14.

[26] C.E. Molina, D.M. Johnson, H. Mehel, R.L. Spatjens, D. Mika, V. Algalarrondo, Z.H. Slimane, P. Lechene, N. Abi-Gerges, H.J. van der Linde, J. Leroy, P.G. Volders, R. Fischmeister, G. Vandecasteele, Interventricular differences in beta-adrenergic responses in the canine heart: role of phosphodiesterases, Journal of the American Heart Association 3(3) (2014) e000858.

[27] N. Milani-Nejad, P.M. Janssen, Small and large animal models in cardiac contraction research: advantages and disadvantages, Pharmacology \& therapeutics 141(3) (2014) 235-49.

[28] W. Zimmermann, H. Scholz, C. Schumacher, H. Wenzlaff, A. Haverich, Effects of saterinone and its enantiomers $\mathrm{R}(+)$-saterinone and $\mathrm{S}(-)$-saterinone on the phosphodiesterase isoenzymes from ventricular tissue of failing human hearts and porcine hearts, Naunyn Schmiedebergs Arch Pharmacol 349(6) (1994) 611-8.

[29] A. Galindo-Tovar, M.L. Vargas, E. Escudero, A.J. Kaumann, Ontogenic changes of the control by phosphodiesterase-3 and -4 of $5-\mathrm{HT}$ responses in porcine heart and relevance to human atrial $5-\mathrm{HT}_{4}$ receptors, British journal of pharmacology 156(2) (2009) 237-49.

[30] A. Galindo-Tovar, M.L. Vargas, A.J. Kaumann, Function of cardiac $\beta_{1^{-}}$and $\beta_{2}$-adrenoceptors of newborn piglets: role of phosphodiesterases PDE3 and PDE4, Eur J Pharmacol 638(1-3) (2010) 99-107. 
[31] T. Podzuweit, R. Bader, P. Nennsteil, A. Müller, Arrythmogenic effects of selective inhibition of cyclic nucleotide phophodiesterase isoenzymes in pig myocardium., Myocardial Ischaemia and Arrhythmia. 5 (1994) 1290-1296.

[32] V. Lambert, A. Capderou, E. Le Bret, C. Rucker-Martin, E. Deroubaix, E. Gouadon, N. Raymond, B. Stos, A. Serraf, J.F. Renaud, Right ventricular failure secondary to chronic overload in congenital heart disease: an experimental model for therapeutic innovation, The Journal of thoracic and cardiovascular surgery 139(5) (2010) 1197-204, 1204 e1.

[33] A. Hodzic, P. Bobin, D. Mika, M. Ly, F. Lefebvre, P. Lechene, E. Le Bret, E. Gouadon, M. Coblence, G. Vandecasteele, A. Capderou, J. Leroy, C. Rucker-Martin, V. Lambert, Standard and strain measurements by echocardiography detect early overloaded right ventricular dysfunction: validation against hemodynamic and myocyte contractility changes in a large animal model, J Am Soc Echocardiogr 30(11) (2017) 1138-1147 e4.

[34] H. Hidaka, H. Hayashi, H. Kohri, Y. Kimura, T. Hosokawa, T. Igawa, Y. Saitoh, Selective inhibitor of platelet cyclic adenosine monophosphate phosphodiesterase, cilostamide, inhibits platelet aggregation, The Journal of pharmacology and experimental therapeutics 211(1) (1979) 26-30.

[35] T. Sudo, K. Tachibana, K. Toga, S. Tochizawa, Y. Inoue, Y. Kimura, H. Hidaka, Potent effects of novel anti-platelet aggregatory cilostamide analogues on recombinant cyclic nucleotide phosphodiesterase isozyme activity, Biochem Pharmacol 59(4) (2000) 347-56.

[36] R.J. Rose, H. Liu, D. Palmer, D.H. Maurice, Cyclic AMP-mediated regulation of vascular smooth muscle cell cyclic AMP phosphodiesterase activity, British journal of pharmacology 122(2) (1997) 233240.

[37] J. Klarenbeek, J. Goedhart, A. van Batenburg, D. Groenewald, K. Jalink, Fourth-generation epacbased FRET sensors for CAMP feature exceptional brightness, photostability and dynamic range: characterization of dedicated sensors for FLIM, for ratiometry and with high affinity, PloS one 10(4) (2015) e0122513.

[38] C.J. Smith, R. Huang, D. Sun, S. Ricketts, C. Hoegler, J.Z. Ding, R.A. Moggio, T.H. Hintze, Development of decompensated dilated cardiomyopathy is associated with decreased gene expression and activity of the milrinone-sensitive CAMP phosphodiesterase PDE3A, Circulation 96(9) (1997) 3116-3123.

[39] B. Ding, J. Abe, H. Wei, Q. Huang, R.A. Walsh, C.A. Molina, A. Zhao, J. Sadoshima, B.C. Blaxall, B.C. Berk, C. Yan, Functional role of phosphodiesterase 3 in cardiomyocyte apoptosis: implication in heart failure, Circulation 111(19) (2005) 2469-2476.

[40] A. Abi-Gerges, W. Richter, F. Lefebvre, P. Mateo, A. Varin, C. Heymes, J.L. Samuel, C. Lugnier, M. Conti, R. Fischmeister, G. Vandecasteele, Decreased expression and activity of cAMP phosphodiesterases in cardiac hypertrophy and its impact on beta-adrenergic cAMP signals, Circulation research 105(8) (2009) 784-92.

[41] W.C. Chiu, J. Kedem, H.R. Weiss, J. Tse, B.V. Cheinberg, P.M. Scholz, Milrinone, a cyclic AMPphosphodiesterase inhibitor, has differential effects on regional myocardial work and oxygen consumption in experimental left ventricular hypertrophy, Cardiovascular research 28(9) (1994) 13601365.

[42] K. Takahashi, T. Osanai, T. Nakano, M. Wakui, K. Okumura, Enhanced activities and gene expression of phosphodiesterase types 3 and 4 in pressure-induced congestive heart failure, Heart Vessels 16(6) (2002) 249-56.

[43] W. Mokni, T. Keravis, N. Etienne-Selloum, A. Walter, M.O. Kane, V.B. Schini-Kerth, C. Lugnier, Concerted regulation of cGMP and cAMP phosphodiesterases in early cardiac hypertrophy induced by angiotensin II, PloS one 5(12) (2010) e14227.

[44] R. Hambleton, J. Krall, E. Tikishvili, M. Honeggar, F. Ahmad, V.C. Manganiello, M.A. Movsesian, Isoforms of cyclic nucleotide phosphodiesterase PDE3 and their contribution to cAMP-hydrolytic activity 
in subcellular fractions of human myocardium, The Journal of biological chemistry 280 (2005) 3916839174.

[45] S. Beca, F. Ahmad, W. Shen, J. Liu, S. Makary, N. Polidovitch, J. Sun, S. Hockman, Y.W. Chung, M. Movsesian, E. Murphy, V. Manganiello, P.H. Backx, Phosphodiesterase type 3A regulates basal myocardial contractility through interacting with sarcoplasmic reticulum calcium ATPase type $2 \mathrm{~A}$ signaling complexes in mouse heart, Circulation research 112(2) (2013) 289-97.

[46] N. Klymiuk, F. Seeliger, Y.M. Bohlooly, A. Blutke, D.G. Rudmann, E. Wolf, Tailored pig models for preclinical efficacy and safety testing of targeted therapies, Toxicol Pathol 44(3) (2016) 346-57.

[47] W. Richter, P. Day, R. Agraval, M.D. Bruss, S. Granier, Y.L. Wang, S.G.F. Rasmussen, K. Horner, P. Wang, T. Lei, A.J. Patterson, B.K. Kobilka, M. Conti, Signaling from $\beta_{1^{-}}$and $\beta_{2}$-adrenergic receptors is defined by differential interactions with PDE4, The EMBO journal 27(2) (2008) 384-393.

[48] F. Afzal, J.M. Aronsen, L.R. Moltzau, I. Sjaastad, F.O. Levy, T. Skomedal, J.B. Osnes, E. Qvigstad, Differential regulation of beta2 -adrenoceptor-mediated inotropic and lusitropic response by PDE3 and PDE4 in failing and non-failing rat cardiac ventricle, British journal of pharmacology 162(1) (2011) 54-71.

[49] V.O. Nikolaev, A. Moshkov, A.R. Lyon, M. Miragoli, P. Novak, H. Paur, M.J. Lohse, Y.E. Korchev, S.E. Harding, J. Gorelik, $ß_{2}$-Adrenergic receptor redistribution in heart failure changes cAMP compartmentation, Science 327 (2010) 1653-7.

[50] V. Timofeyev, R.E. Myers, H.J. Kim, R.L. Woltz, P. Sirish, J.P. Heiserman, N. Li, A. Singapuri, T. Tang, V. Yarov-Yarovoy, E.N. Yamoah, H.K. Hammond, N. Chiamvimonvat, Adenylyl cyclase subtype-specific compartmentalization: differential regulation of L-type $\mathrm{Ca}^{2+}$ current in ventricular myocytes, Circulation research 112(12) (2013) 1567-76.

[51] R.E. Weishaar, D.C. Kobylarz-Singer, R.P. Steffen, H.R. Kaplan, Subclasses of cyclic AMP-specific phosphodiesterase in left ventricular muscle and their involvement in regulating myocardial contractility, Circulation research 61 (1987) 539-547.

[52] S.A. Harrison, D.H. Reifsnyder, B. Gallis, G.G. Cadd, J.A. Beavo, Isolation and characterization of bovine cardiac muscle cGMP-inhibited phosphodiesterase: a receptor for new cardiotonic drugs, Molecular pharmacology 29 (1986) 506-514.

[53] C.J. Smith, J. He, S.G. Ricketts, J.Z. Ding, R.A. Moggio, T.H. Hintze, Downregulation of right ventricular phosphodiesterase PDE-3A mRNA and protein before the development of canine heart failure, Cell Biochem Biophys 29(1-2) (1998) 67-88.

[54] F. Ahmad, W. Shen, F. Vandeput, N. Szabo-Fresnais, J. Krall, E. Degerman, F. Goetz, E. Klussmann, M. Movsesian, V. Manganiello, Regulation of sarcoplasmic reticulum $\mathrm{Ca}^{2+}$ ATPase 2 (SERCA2) activity by phosphodiesterase $3 A$ (PDE3A) in human myocardium: phosphorylation-dependent interaction of PDE3A1 with SERCA2, The Journal of biological chemistry 290(11) (2015) 6763-76.

[55] A. Martinez, C. Gil, cAMP-specific phosphodiesterase inhibitors: promising drugs for inflammatory and neurological diseases, Expert Opin Ther Pat 24(12) (2014) 1311-21. 


\section{FIGURE LEGENDS}

\section{Figure 1. Effect of PDE4 or PDE3 inhibition on cAMP homeostasis in APVMs}

(A, B) Time courses of the CFP/YFP ratio upon $\beta$-AR stimulation by Iso (10 nM) (A) or under basal conditions (B), after addition of the PDE3 inhibitor Cilostamide (Cil, $1 \mu \mathrm{M})$, the PDE4 inhibitor Ro 20-1724 (Ro, $10 \mu \mathrm{M})$ or combination of both inhibitors in APVMs expressing the cAMP sensor Epac-S ${ }^{\mathrm{H} 187}$. Pseudo-color images of the CFP/YFP ratio were recorded the times indicated by the letters on the graphs (A). (C, D) Mean variation ( \pm SEM) of the normalized CFP/YFP ratio for each condition tested. Numbers indicate the number of cells from 3 pigs. Statistical significance is indicated as ${ }^{*}, \mathrm{p}<0.05,{ }^{* *}, \mathrm{p}<0.01$; ${ }^{* *}, \mathrm{p}<0.001$; a Kruskal-Wallis followed by a Dunn's post hoc test.

\section{Figure 2. Effect of PDE3 or PDE4 inhibition on EC coupling in APVMs}

(A) Representative traces of $\mathrm{Ca}^{2+}$ transients and sarcomere length variation $\left(\Delta \mathrm{L} / \mathrm{L}_{0}\right)$ recorded in Fura-2-loaded APVMs paced at $1 \mathrm{~Hz}$ in basal conditions (Ctrl), after addition of the PDE4 inhibitor (Ro 20-1724, Ro, $10 \mu \mathrm{M}$ ) alone or in combination with the PDE3 inhibitor (Cilostamide, Cil, $1 \mu \mathrm{M})$. (B) Mean amplitude ( \pm SEM) of $\mathrm{Ca}^{2+}$ transients and average relaxation kinetics Tau ( \pm SEM) for each condition tested. (C) Sarcomere shortening and average relaxation kinetics Tau $( \pm$ SEM) for all conditions tested. Numbers indicate the number of cells from 3 pigs. Statistical significance is indicated as: ${ }^{*}, p<0.05 ;{ }^{* *}, p<0.01 ;{ }^{* *}, p<0.001$; a nested ANOVA followed by Tukey's post-hoc test was used to analyse $\mathrm{Ca}^{2+}$ transients and sarcomere shortening amplitudes. A Kruskal-Wallis followed by a Dunn's post hoc test was used to compare relaxation kinetics.

Figure 3. Simultaneous PDE4 and PDE3 inhibition promotes pro-arrhythmogenic spontaneous calcium waves in APVMs

(A) Representative traces of $\mathrm{Ca}^{2+}$ transients in Fura-2 loaded APVMs paced at $1 \mathrm{~Hz}$. The occurrence of spontaneous $\mathrm{Ca}^{2+}$ waves (SCWs) was evaluated during a $10 \mathrm{~s}$ pause in pacing. This protocol was repeated in basal conditions (Ctrl), during PDE4 or PDE3 inhibition by either Ro 20-1724 (Ro) or cilostamide (Cil) respectively, and upon concomitant PDE4 and PDE3 inhibition (Ro + Cil). (B) Average number of SCWs ( \pm SEM) in all conditions tested. Numbers indicate the number of cells obtained from 4 pigs. (C) Proportion of arrhythmic cells for all conditions tested. Numbers indicate the number of arrhythmic cells over all cells assessed in each condition. Statistical significance is indicated as: ${ }^{*}, p<0.05 ;{ }^{* *}, p<0.01$. A Kruskal-Wallis followed by a Dunn's post hoc test was used to compare the occurrence of SCWs in the different 
experimental conditions and a $\mathrm{Chi}^{2}$ test followed by a Fischer exact test was used to compare the percent of arrhythmic cells.

Figure 4. Concomitant PDE3 and PDE4 inhibition leads to inotropic, lusitropic and the occurrence of SCWs in APVMs isolated from a model of combined RV overload reproducing repaired tetralogy of Fallot

(A) Representative traces of $\mathrm{Ca}^{2+}$ transients and sarcomere length variation $\left(\Delta \mathrm{L} / \mathrm{L}_{0}\right)$ recorded in a Fura 2- loaded APVM isolated from a repaired tetratology of Fallot (rTOF) pig and paced at $1 \mathrm{~Hz}$. Basal conditions (Ctrl) and after addition of PDE4 inhibitor alone (Ro 20-1724, Ro, $10 \mu \mathrm{M}$ ) or additional PDE3 inhibition (Cilostamide, Cil, $1 \mu \mathrm{M})($ Ro + Cil). (B) Mean amplitude ( \pm SEM) of $\mathrm{Ca}^{2+}$ transients and decay kinetic (Tau \pm SEM) of $\mathrm{Ca}^{2+}$ transients for each condition tested. (C) Sarcomere shortening and average relaxation kinetic (Tau \pm SEM) for all conditions tested. (D) Representative traces of $\mathrm{Ca}^{2+}$ transients in Ctrl, upon Ro and Ro + Cil when exhibiting a SCW. (E) Average number of SCWs ( \pm SEM) in all conditions tested. (F) Proportion of arrhythmic cells for all conditions tested. Numbers indicate the number of cells from 3 pigs. Statistical significance is indicated as: ${ }^{*}, \mathrm{p}<0.05 ;{ }^{*}, \mathrm{p}<0.01$; ${ }^{* *}, \mathrm{p}<0.001$; a Kruskal-Wallis followed by a Dunn's post hoc test was used to analyse $\mathrm{Ca}^{2+}$ transients, sarcomere shortening amplitudes and to compare the occurrence of SCWs in the different experimental conditions. A Chi ${ }^{2}$ test followed by a Fischer exact test was used to compare the percent of arrhythmic cells.

Figure 5. Similarly to PDE3 inhibition, PDE4 inhibition enhances EC coupling in APVMs upon $\beta$-AR stimulation

(A,B) Representative traces of $\mathrm{Ca}^{2+}$ transients and sarcomere length variation $\left(\Delta \mathrm{L} / \mathrm{L}_{0}\right)$ recorded simultaneously in Fura-2-loaded APVMs paced at $1 \mathrm{~Hz}$ in basal conditions (Ctrl), upon $\beta-A R$ stimulation by Iso (10 nM) alone or with PDE4 inhibitor (Ro 20-1724, Ro, $10 \mu \mathrm{M}$, A) or PDE3 inhibitor (Cilostamide, Cil, $1 \mu \mathrm{M}, \mathrm{B})$. (C) Mean amplitudes ( \pm SEM) and relaxation kinetics Tau ( \pm SEM) of $\mathrm{Ca}^{2+}$ transients and sarcomere shortening for Ctrl, Iso, and Iso + Ro. (D) Mean amplitude $( \pm S E M)$ and relaxation kinetics Tau ( \pm SEM) of $\mathrm{Ca}^{2+}$ transients and sarcomere shortening for Ctrl, Iso, and Iso + Cil. Numbers indicate the number of cells obtained from 4 pigs. Statistical significance is indicated as: ${ }^{*}, \mathrm{p}<0.05$; ${ }^{* *}, \mathrm{p}<0.01$; ${ }^{* *}, \mathrm{p}<0.001$; a nested ANOVA followed by Tukey's post-hoc test was used to analyse $\mathrm{Ca}^{2+}$ transients and sarcomere shortening amplitudes. A Kruskal-Wallis followed by a Dunn's post hoc test was used to compare relaxation kinetics. 
Figure 6. PDE4 inhibition like PDE3 inhibition, promotes pro-arrhythmogenic spontaneous calcium waves in APVMs upon $\beta$-AR stimulation

(A) Representative traces of $\mathrm{Ca}^{2+}$ transients in Fura-2-loaded APVMs paced at $1 \mathrm{~Hz}$. The occurrence of spontaneous $\mathrm{Ca}^{2+}$ waves (SCWs) was evaluated during a $10 \mathrm{~s}$ pause in pacing. This protocol was repeated in basal conditions (Ctrl), upon $\beta$-AR stimulation with isoproterenol (Iso, $10 \mathrm{nM}$ ) alone or with PDE4 inhibition by Ro 20-1724 (Iso + Ro), or PDE3 inhibition by cilostamide (Iso + Cil). (B) Average number of SCWs ( \pm SEM) in all conditions tested. Numbers indicate the number of cells obtained from 4 pigs. (C) Proportion of arrhythmic cells for all conditions tested. Numbers indicate the number of arrhythmic cells over all cells assessed for each condition. Statistical significance is indicated as: ${ }^{*}, p<0.05 ;{ }^{* *}, p<0.01 ;{ }^{* *}, p<0.001$. a Kruskal-Wallis followed by a Dunn's post hoc test was used to compare the occurrence of SCWs, and a $\mathrm{Chi}^{2}$ test followed by a Fischer exact test was used to compare the percent of arrhythmic cells.

Figure 7. PDE3A and PDE4 subtypes expression in right ventricle tissue and isolated cardiomyocytes from pigs

Western blots showing PDE3A, PDE4A, PDE4B and PDE4D protein expression in right ventricle tissues (A) or isolated cardiomyocytes from right ventricles (B) of 3 different pigs. Calsequestrin (CSQ) or GAPDH were used as loading controls. For specific PDE4A and PDE4B detection, rabbit polyclonal antibodies generated against their respective $C$-termini were used (anti-PDE4A: AC55; anti-PDE4B: 113-4). Mouse monoclonal antibody (ICOS PDE4D) was used to specifically detect PDE4D. $15 \mu \mathrm{g}$ proteins from protein extracts were loaded. 


\section{SUPPLEMENTAL MATERIAL}

\section{METHODS}

\section{Experimental model of combined right ventricular overload}

Surgical procedure mimicking repaired Tetralogy of Fallot (rTOF) was performed on-50 to 67 days old male piglets as previously described. ${ }^{1,2}$ After premedication with ketamine hydrochloride (15 mg/kg intramuscularly), general anaesthesia was induced with $1 \%$ propofol and cisatracurium (0,3 mg/kg each 2 hours), allowing endotracheal intubation, and maintained with isoflurane in $100 \%$ oxygen (Servo 900, Siemens-Elema AB, Solna, Sweden). Through a left thoracotomy approach, a side-biting vascular clamp was longitudinally placed across the pulmonary valve annulus without obstruction of the RV outflow tract. A pulmonary valve leaflet was excised, and the pulmonary infundibulum, annulus, and trunk were enlarged by a $2 \mathrm{~cm}$-long elliptically shaped polytetrafluorethylene patch to ensure loss of valve integrity. This chronic pulmonary valve regurgitation led to a right ventricular $(R V)$ volume overload. The RV pressure overload was achieved by pulmonary artery banding, made of umbilical tape, placed around the artery truncus and secured for a final diameter of approximately $1 \mathrm{~cm}$ to ensure a progressive pulmonary stenosis with animal growth. Control animals did not have sham surgery. Animals were sacrificed $\sim 4$ months (Day 164-222) after surgical procedure.

\section{Echocardiographic analysis}

Echocardiography was performed on closed-chest animals under general anesthesia in dorsal decubitus. We used commercially available Vivid E9 ultrasound machine (General Electric Medical System, Milwaukee, WI, USA) equipped with a $2.5 \mathrm{MHz}$ transducer. The values of all echocardiographic parameters were obtained as the average value of three consecutive cardiac cycles during transient apnoea and were analyzed on a comprehensive workstation (EchoPAC 110.1.2, GE-Healthcare, Horten, Norway). The echocardiographic analysis used for RV morphological and functional assessment in this model was previously detailed by our group. ${ }^{2}$ Briefly, RV morphology was assessed by RV anterior wall thickness, the right on left ventricle end-diastolic diameter ratio, the tricuspid on mitral annular diameter ratio, and RV end-diastolic (RVED) and end-systolic (RVES) areas. RV systolic function was assessed by the RV fractional area change (FAC), the Tricuspid Annular Plane Systolic Excursion (TAPSE), and the peak systolic velocity (S'). Pulmonary annulus diameter and transpulmonary gradient through the pulmonary band were both measured to evaluate the degree of pulmonary stenosis. The severity of pulmonary regurgitation was assessed using color Doppler flow. ${ }^{3}$ 


\section{Statistical analyses}

Analyses were performed with statistical software GraphPad (Prism5, GraphPadSoftware, http://www.graphpad.com). Echocardiography data were tested for normality and expressed as median and range after the result of the Shapiro-Wilk test. The 2 groups (control and operated) were compared by Mann-Whitney $U$ test. Differences between the mean values of two groups of lonoptix results were analyzed by an unpaired Student's $t$-test.

\section{References:}

1. Lambert V, Capderou A, Le Bret E, Rucker-Martin C, Deroubaix E, Gouadon E, Raymond N, Stos B, Serraf A, Renaud JF. Right ventricular failure secondary to chronic overload in congenital heart disease: an experimental model for therapeutic innovation. J Thorac Cardiovasc Surg. 2010;139:1197-1204, 1204 e1191

2. Hodzic A, Bobin P, Mika D, Ly M, Lefebvre F, Lechene P, Le Bret E, Gouadon E, Coblence M, Vandecasteele G, Capderou A, Leroy J, Rucker-Martin C, Lambert V. Standard and strain measurements by echocardiography detect early overloaded right ventricular dysfunction: validation against hemodynamic and myocyte contractility changes in a large animal model. $J$ Am Soc Echocardiogr. 2017;30:1138-1147 e1134

3. Renella P, Aboulhosn J, Lohan DG, Jonnala P, Finn JP, Satou GM, Williams RJ, Child JS. Two-dimensional and Doppler echocardiography reliably predict severe pulmonary regurgitation as quantified by cardiac magnetic resonance. J Am Soc Echocardiogr. 2010 23:880-6 
Table 1: Echocardiographic characteristics: standard parameters of right ventricular morphology and systolic function in the porcine model of combined right ventricular overload reproducing repaired tetralogy of Fallot (rTOF)

\begin{tabular}{|c|c|c|}
\hline & Healthy & rTOF \\
\hline $\begin{array}{l}\text { Clinical characteristics } \\
\text { Age }(\mathrm{d}) \\
\text { Weight }(\mathrm{kg})\end{array}$ & $\begin{array}{r}161(149 \text { to } 170) \\
45(40 \text { to } 55)\end{array}$ & $\begin{array}{r}196(164 \text { to } 222) \\
50(37.8 \text { to } 68)\end{array}$ \\
\hline $\begin{array}{l}\text { RV dimensions } \\
R V_{E D} \text { area }\left(\mathrm{cm}^{2}\right) \\
R V_{E S} \text { area }\left(\mathrm{cm}^{2}\right) \\
R V / L V_{E D} \text { diameter ratio } \\
\mathrm{T} / \mathrm{M} \text { diameter ratio } \\
\mathrm{PA} \text { annulus diameter }(\mathrm{cm}) \\
\mathrm{RV} \text { wall thickness }(\mathrm{mm})\end{array}$ & $\begin{array}{r}8.7(8.0 \text { to } 11.4) \\
4.9(4.4 \text { to } 6.0) \\
0.43(0.4 \text { to } 0.53) \\
0.74(0.70 \text { to } 0.81) \\
1.9(1.8 \text { to } 2.0) \\
3.0(3.0 \text { to } 3.4) \\
\end{array}$ & $\begin{array}{r}21.6(16.7 \text { to } 26.2) \text { * } \\
14.4(9.3 \text { to } 15.0) \text { * } \\
0.94(0.84 \text { to } 1.51) \text { * } \\
1.23(1.12 \text { to } 1.84) \text { * } \\
2.3(2.1 \text { to } 3.0) \text { * } \\
6.2(4.6 \text { to } 7.5) \text { * }\end{array}$ \\
\hline $\begin{array}{l}\text { Trans-pulmonary gradient }(\mathrm{mmHg}) \\
\text { Maximal } \\
\text { Mean }\end{array}$ & $\begin{array}{l}2.8(2.0 \text { to } 4.0) \\
1.3(1.0 \text { to } 2.0)\end{array}$ & $\begin{array}{l}33.4(25.0 \text { to } 39.7) \text { * } \\
19.5(13.2 \text { to } 22.4) \text { * }\end{array}$ \\
\hline $\begin{array}{l}\text { RV systolic function indices } \\
\text { FAC }(\%) \\
\text { TAPSE }(\mathrm{mm}) \\
\text { Peak S' }(\mathrm{cm} / \mathrm{s})\end{array}$ & $\begin{array}{r}45.3(43.5 \text { to } 57.0) \\
20.0(17.0 \text { to } 21.0) \\
8.0(8.0 \text { to } 10.0)\end{array}$ & $\begin{array}{r}37.0(33.0 \text { to } 53.2) \\
14(11.35 \text { to } 17.5)^{*} \\
7.0(5.5 \text { to } 9.1)\end{array}$ \\
\hline
\end{tabular}

Data are presented as the median and interquartile range. ${ }^{*}, \mathrm{p}<0.05$ rTOF group (N=7) versus controls $(\mathrm{N}=12)$.

ED: end-diastolic; ES: end-systolic; FAC: fractional area change; LV: left ventricle; PA: pulmonary artery; RV: right ventricle; TAPSE: tricuspid annular plane systolic excursion; T/M: Tricuspid/Mitral. 
Table 2: Characteristics of sarcomere shortening and calcium transients measured simultaneously in right ventricular myocytes isolated from Control and rTOF animals

\begin{tabular}{|l|l|l|l|l|}
\hline & $\begin{array}{l}\text { Sarcomere } \\
\text { Shortening } \\
\text { (\% of resting } \\
\text { length) }\end{array}$ & $\begin{array}{l}\text { Tau } \\
\text { relaxation }(\mathbf{s})\end{array}$ & $\begin{array}{l}\mathbf{C a}^{2+} \text { transient } \\
\text { amplitude } \\
(\% \text { of diastolic } \\
\text { ratio) }\end{array}$ & $\begin{array}{l}\text { Tau decrease of } \mathbf{C a}^{2+} \\
\text { transient } \\
(\mathbf{s})\end{array}$ \\
\hline$\underline{\text { Healthy }}$ & $\begin{array}{l}1.6 \pm 0.3 \\
(\mathrm{n}=34)\end{array}$ & $\begin{array}{l}0.2 \pm 0.03 \\
(\mathrm{n}=33)\end{array}$ & $\begin{array}{l}20.5 \pm 1.8 \\
(\mathrm{n}=34)\end{array}$ & $\begin{array}{l}0.4 \pm 0.02 \\
(\mathrm{n}=34)\end{array}$ \\
\hline$\underline{\underline{\mathbf{T O F}}}$ & $\begin{array}{l}1.3 \pm 0.4 \\
(\mathrm{n}=19)\end{array}$ & $\begin{array}{l}0.3 \pm 0.04^{*} \\
(\mathrm{n}=19)\end{array}$ & $\begin{array}{l}19.8 \pm 1.9 \\
(\mathrm{n}=19)\end{array}$ & $\begin{array}{l}0.51 \pm 0.05 * \\
(\mathrm{n}=19)\end{array}$ \\
\hline
\end{tabular}

Data are presented as the mean \pm SEM. ${ }^{*}, \mathrm{p}<0.05$, rTOF group $(\mathrm{N}=3)$ versus controls $(\mathrm{N}=7)$.

\section{SUPPLEMENTAL FIGURE LEGENDS}

Supplemental Figure 1. Effect of PDE4 or PDE3 inhibition on cAMP homeostasis in APVMs isolated from the rTOF pig model

(A, B) Time courses of the CFP/YFP ratio upon PDE3 inhibition (Cilostamide, Cil, $1 \mu \mathrm{M}$ ) or PDE4 inhibition (Ro 20-1724, Ro, $10 \mu \mathrm{M}$ ) or concomitant inhibition (Ro + Cil) (A) and upon $\beta$-AR stimulation (B) by Iso $(10 \mathrm{nM})$ alone or with Ro in APVMs expressing the cAMP sensor Epac$S^{H 187}$. (C, D) Mean variation ( \pm SEM) of the normalized CFP/YFP ratio upon application of the PDE inhibitors alone (Cil, Ro) or in combination (Ro + Cil) and upon $\beta$-AR stimulation by Iso (10 $\mathrm{nM})$ alone and after addition of Ro $(10 \mu \mathrm{M})$ or Cil $(1 \mu \mathrm{M})$. Numbers indicate the number of cells from 2 pigs. Statistical significance is indicated as *, $\mathrm{p}<0.05$; Kruskal-Wallis followed by Dunn's multiple comparison post hoc test. 